\title{
Flood Discharge Estimation using Wavelet Transform (Case Study: Tamer Watershed)
}

\author{
Bagher Heidarpour \\ Department of Civil \\ Engineering, Young \\ Researchers and Elite \\ Club, \\ Roudsar and Amlash \\ Branch, \\ Islamic Azad University, \\ Roudsar, Iran
}

\author{
Sajad Shahabi \\ Department of Civil \\ Engineering, \\ Young Researchers \\ and Elite Club, \\ Roudsar and Amlash \\ Branch, \\ Islamic \\ Azad University, \\ Roudsar, Iran
}

\author{
Bahman Panjalizadeh \\ Marseh \\ Department of Civil \\ Engineering, \\ Young \\ Researchers and Elite \\ Club, \\ Roudsar and Amlash \\ Branch, Islamic Azad \\ University, \\ Roudsar, Iran
}

\author{
Aziz Hosseinnezhad \\ Department of Civil \\ Engineering, \\ Young Researchers \\ and Elite Club, \\ Roudsar and Amlash \\ Branch, \\ Islamic \\ Azad University, \\ Roudsar, Iran
}

\begin{abstract}
In this study, we present a method to carry out flood frequency analysis when the assumption of stationary is not valid. A wavelet transform model is used to flood discharge estimation. A full series is applied to flood discharge estimation using two different wavelet functions. The energy function of wavelet was used to estimate flood discharge. The data were decomposed into some details and one approximation through different wavelet functions and decomposition levels. The approximation series was employed to estimate flood discharge. This was performed using daily maximum discharge data from on the Tamer hydrodynamic station in the north of Iran. In this way, the data from 1970 to 2009 were evaluated by wavelet analysis. Results illustrate that the decomposition levels in wavelet transform have a significant role in the flood discharge estimation. For instance, in 100years return period, the flood discharges are 13.06 and 110.92 by Haar (db1) mother wavelet in decomposition level of 1 and 8, respectively. It is shows a more than 8 time growth in flood discharge. The higher decomposition levels are closer to traditional statistical methods such as annual maximum and partial duration series.
\end{abstract}

\section{Keywords}

Flood Discharge Estimation, Tamer Watershed, Haar, Daubechies, Time Series, wavelet Transform.

\section{INTRODUCTION}

Chow et al. (2013) reported that flood discharge estimation has a significant role in prevent from damages to establishment. Inattention to estimation of flood risk can be lead to irreparable damages, so in last half of century, many different methods were presented in this branch of hydrology. Most of these studies are based on statistical distributions. Some of these researches were presented by Chow et al. [1]. On the other hand many studies and researches in flood discharge estimation indicate the importance of this very important branch of hydrology. Damages of recent huge floods in the world indicate the result of inattention to this nature phenomena or mistakes in flood discharge estimation. Despite decades study on flood discharge estimation, the new approaches are being developed and the older approaches are improved which shows the importance of new research in flood discharge estimation. Hence, increasing the accuracy of flood discharge estimation has been considered by many researchers. Stationary data is employed in most of traditional methods including annual maximum (AM) and partial duration (PD).

The stationary of data is the most important assumption of hydrologic studies. The hydrologic data used should be carefully picked out so that the assumptions of stationary and identical distribution are satisfied. In traditional researches, this is mostly achieved by picking out the AM of the variable being analyses with the expectation that the successive observations of it from year to year will be independent [1].

Many studies have been carried out on flood discharge estimation. These studies include several different approaches from traditional approaches, such as AM and PD, index flood, etc. to newer approaches such as fuzzy clustering [2] and regional flood frequency $[3,4,5]$. So many studies in this important branch of hydrology can be found in the hydrological literature. Some of these researches listed below: A framework for flood discharge estimation is developed based on Generalized Adaptive Models for Location, Scale and Shape parameters (GAMLSS), a tool for modeling time series under non-stationary conditions. GAMLSS is employed to AM records for Little Sugar Creek. It is presented that GAMLSS is able to describe the variability in the mean and variance of the AM peak discharge [6].

Regional flood frequency analysis is the most popular approach in flood frequency analysis for watersheds that have not enough data for flood discharge estimation. This approach was employed frequently and developed in recent decades [3, $7,8,9]$.

Several studies using some other approaches such as indexfloods and combining self-organizing feature maps carried out regional flood frequency analysis [7,2].

Some other approaches such as fuzzy expert system (FES) are being employed in flood discharge estimation. In this study the performance of the FES were improved by tuning of the membership functions of the fuzzy sets using a genetic algorithm (GA) [9].

Karthikeyan and Kumar (2013) were carried out a study to ascertain the predictability of non-stationary time series using wavelet and Empirical Mode Decomposition (EMD) based time series models, which were developed in the past to decompose a time series into components. Their studies present that the wavelet based approach has better forecasting 
capabilities over the EMD based approach despite some of the limitations of time series approaches and the manner in which decomposition takes place [10]. In a review paper, application wavelet transform approaches in hydrology were introduced. In this paper application of wavelet transform in different aspects was investigated [11].

The main objective of this paper is to present a non-stationary model for estimation of flood risk, comparison with traditional approaches and finally, improvement of flood risk estimation accuracy.

\section{STUDY AREA AND DATA}

Tamer watershed with approximately 1531 square kilometer in area is located in the southeastern part of the Caspian Sea coastline in Iran. It is one of the main subwatersheds of Golestan watershed. This area is located between $55^{\circ} 30^{\prime}$ and $56^{\circ} 4^{\prime}$ E longitude and $37^{\circ}, 24^{\prime}$ to $37^{\circ}, 48^{\prime} \mathrm{N}$ latitude. Fig. 1 shows the map of Tamer watersheds.

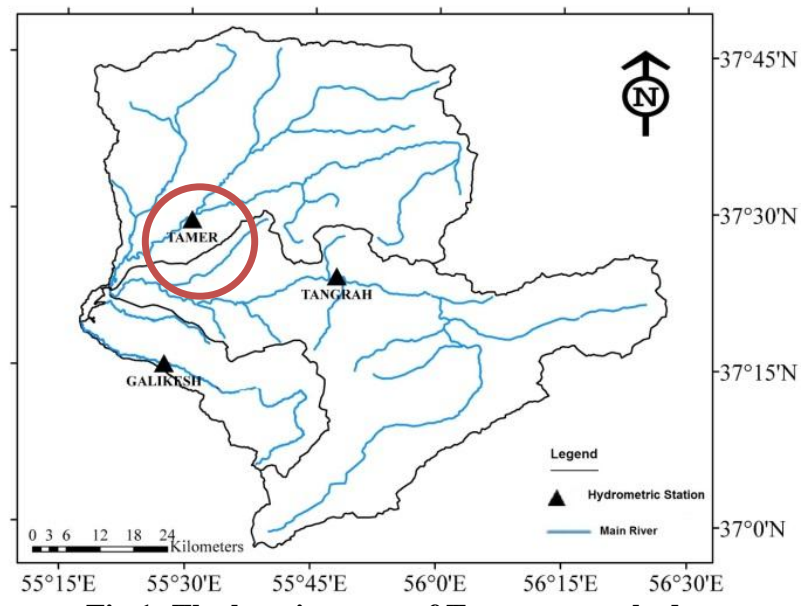

Fig 1: The location map of Tamer watershed

\section{WAVELET TRANSFORM}

The wavelet transform applications are increased in recent years. The wavelet transform is a tool to decompose a signal into its subseries in time and frequency domains. It is the derivative from of Fourier transform. Fig. 1 shows a schematic diagram of wavelet transform. It has been used for studying non-stationary time series unlike Fourier transform. This issue is the most important benefit of wavelet transform. In traditional transformation methods such as Fourier transform, production of both time and frequency information with a higher resolution is impossible, but wavelet transform resolved this deficiency $[12,13]$.

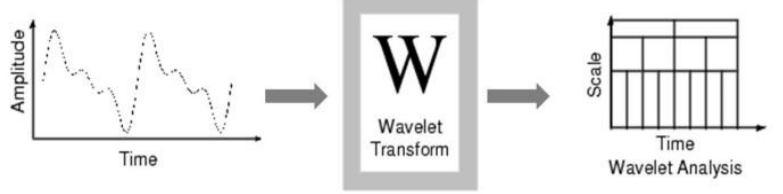

Fig 2: A schematic diagram of wavelet transforms Continues wavelet transform (CWT) and discrete wavelet transform (DWT) are two types of wavelet transform. The wavelet transform of a continues time series, $f(t)$, is defined as:

$T(s, b)=\frac{1}{\sqrt{s}} \int_{-\infty}^{+\infty} \varphi^{*}\left(\frac{t-b}{s}\right) f(t) d t$

where $\varphi(t), s, b$ and $t$ are the mother wavelet function, dilation factor (or contraction coefficient), scale parameter and time, respectively. As well as * corresponds to the complex conjugate.

The mother wavelet function is described by: $\varphi(b, s)=\frac{1}{s} \varphi\left(\frac{t-b}{s}\right)$

This function is used for both wavelet decomposition and composition transforms. Here, the Haar and Daubechies wavelet functions were used for the analysis.

\subsection{Haar Wavelet}

Previous works shows that any discussion of wavelets begins with Haar wavelet, the first and the simplest. Haar wavelet is discontinuous, and resembles a step function. The Haar represents the same wavelet as Daubechies db1. Also, the Haar scale function is shows as [12]:

$$
\begin{array}{ll}
\varphi(x)=1 & \text { if } x \in[0,1] \\
\varphi(x)=0 & \text { if } x \notin[0,1]
\end{array}
$$

It is discontinuous and similar step function. The Haar is like db1. The Eqs. (7) to (9) show Haar wave function[12]:

$$
\begin{array}{ll}
\psi(x)=1 & x \in[0,0.5] \\
\psi(x)=-1 & x \in[0.5,1] \\
\psi(x)=0 & x \notin[0.0,1]
\end{array}
$$

The Haar wave and scale functions are shown in Fig. 3 and Fig, 4, respectively [12].

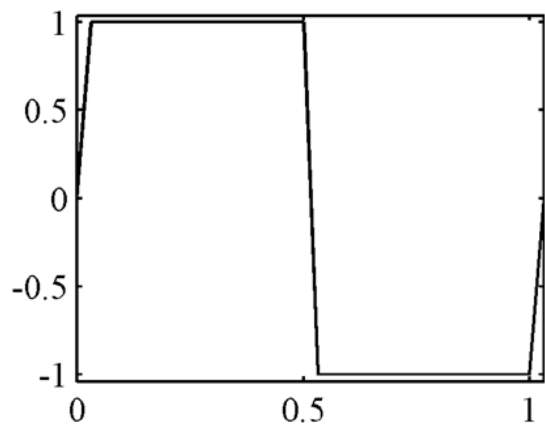

Fig 3: Haar wave function

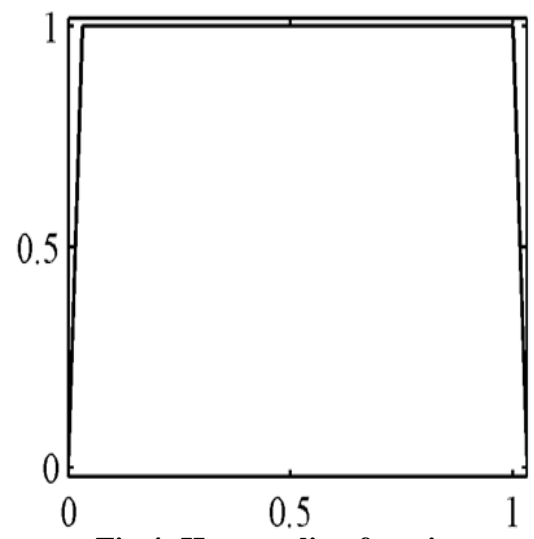

Fig 4: Haar scaling function

\subsection{Daubechies Wavelet}

Ingrid Daubechies, one of the most distinguish scientist in the wavelet researches, presented what is called compactly supported orthonormal wavelets, thus making discrete wavelet analysis practicable.

The Daubechies family wavelets names are written $\mathrm{dbN}$, where $\mathrm{N}$ is the order, and $\mathrm{db}$ is the "surname" of the wavelet. The db1, is the same as Haar wavelet [12].

Most of these family functions are not. Functions regularity of this family is increased with increasing their orders. This family is also orthogonal [12]. 


\section{RESULTS AND DISCUSSIONS}

In this study, flood discharge estimation was performed using wavelet transforms, so a time series of Tamer hydrometric station discharge data was used to make wavelet model. Fig. 5 shows this time series. The MATLAB software, Version 7.8.0.347(R2009a), and its wavelet toolbox were used for the wavelet analysis.

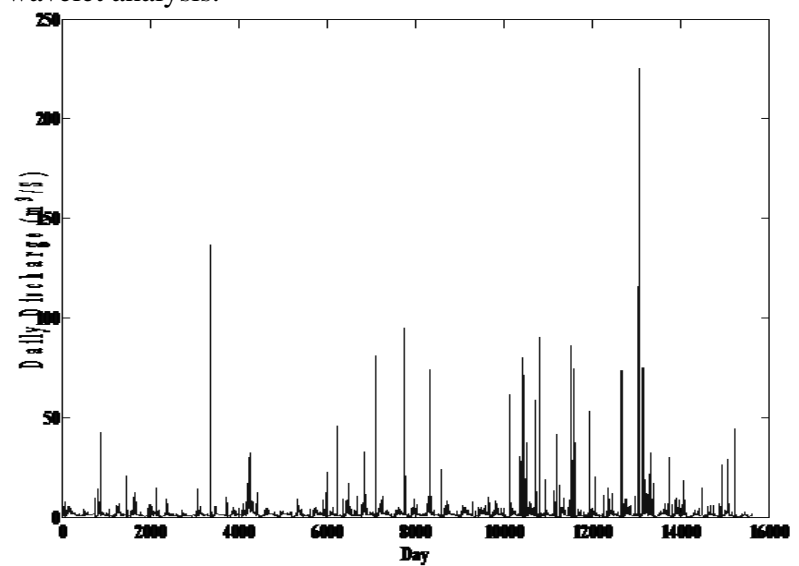

Fig 5: Tamer station time series (1970- 2009).

After preparing the time series, next step is to select the wavelet function and its decomposition level. When wavelet transform is used, the selection of wavelet function and the optimized decomposition level are the most important parameter. One of the important points is choosing mother wavelet based on phenomena natural and series type. So each mother wavelet function pattern that make a better set adaption in geometry aspect to time series, gets better results. After choosing the wavelet function, the next important step is the selection of decomposition level. In this method, the time series are decomposed into their sub-series by using the wavelet.

At first, time series was decomposed to an approximation TS and some details (depend on decomposition levels), and then the approximation time series was used to flood discharge estimation. Here the simplest and first wavelet (Haar) and Daubechies wavelet were employed.

To estimate flood discharge, the time series were decomposed to an approximation and some details. In this study two mother wavelet were employed, Haar and Daubechies. Fig. 6 and Fig. 7 show these decompositions of time series at 8 decomposition levels by Haar and Daubechies3, respectively. In these two figures the main plot's horizontal axis and vertical axis are day of discharge and discharge data in $\mathrm{m}^{3} / \mathrm{sec}$, respectively.
Approiciation As

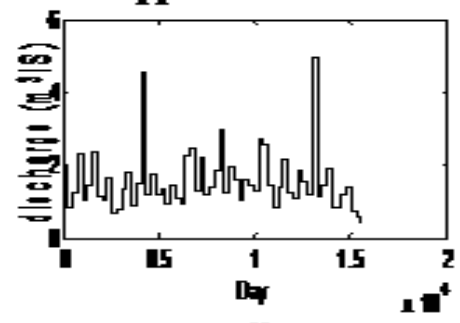

Det:i1D3

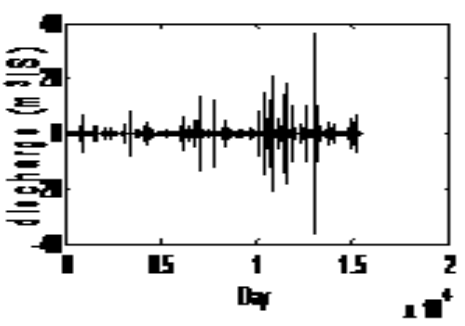

Deti106

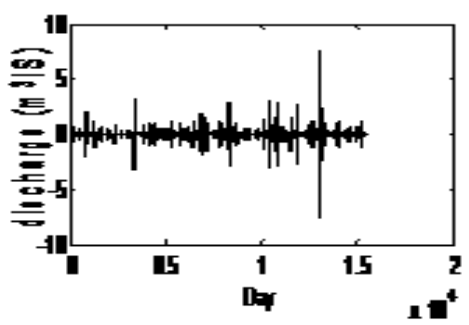

DetailD1

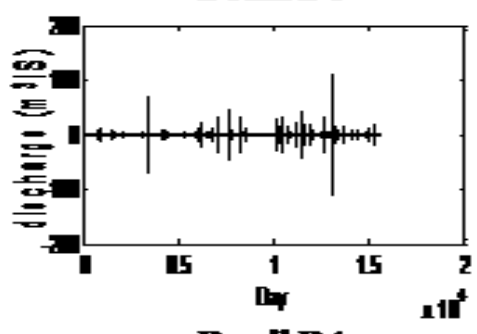

DetailD4

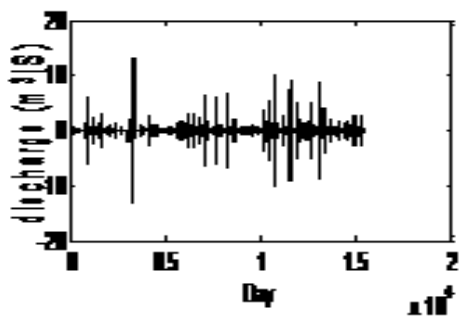

DetalD7

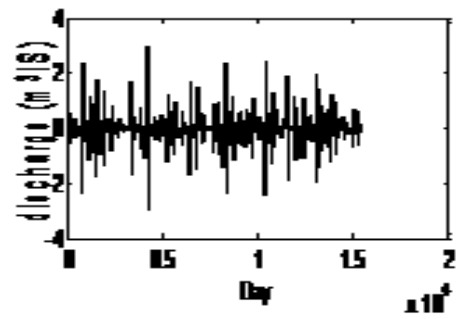

Det: $\mathrm{D} 2$

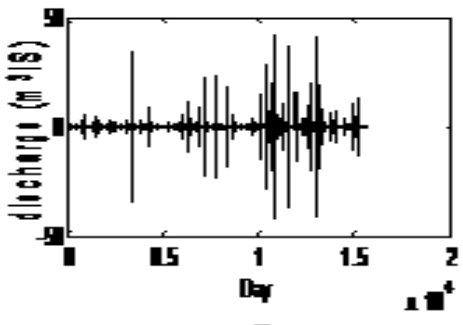

Deta? DS

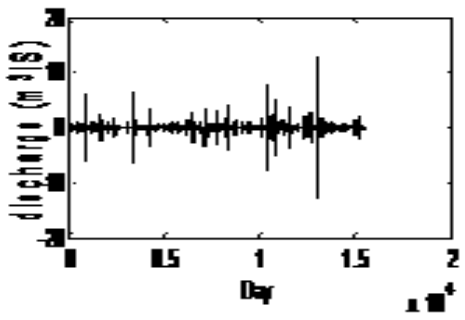

Dat? DR

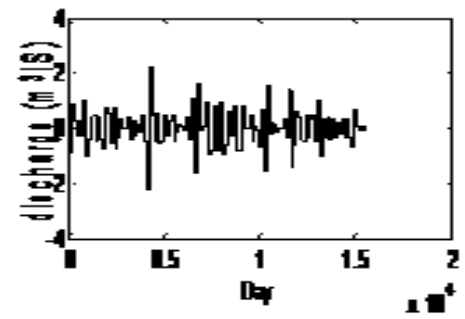

Fig 6: The decomposed discharge time series by Haar at level 8 


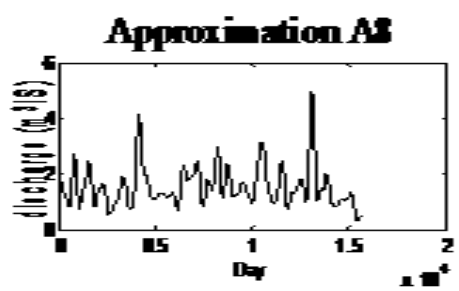

Detail D3

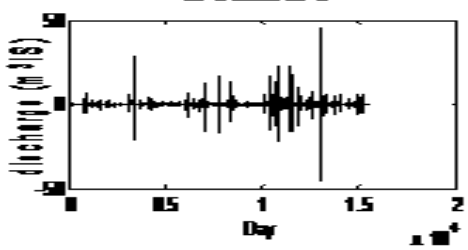

Detail D6

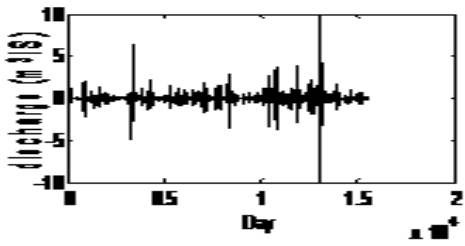

Detail D1

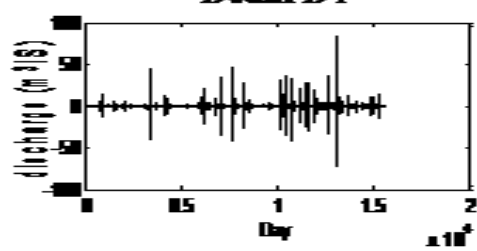

Detail D4

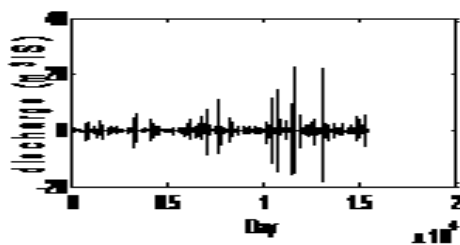

Detail D7

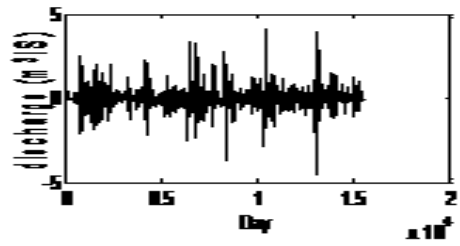

Deta 102

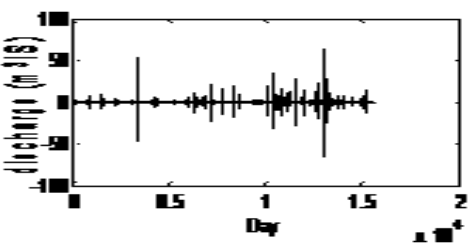

Det? DS

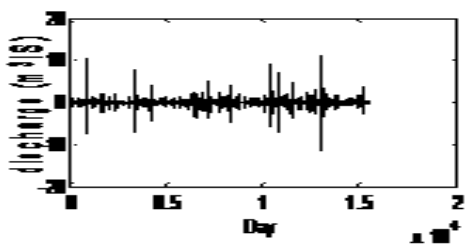

Deta DS

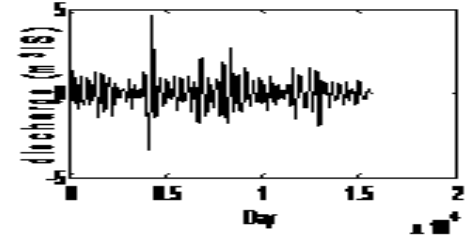

Fig 7: The decomposed discharge time series by db4 at level 8

Table 1. Flood discharge estimation $\left(\mathrm{m}^{3} / \mathrm{Sec}\right)$

\begin{tabular}{cccccccc}
\hline \multicolumn{2}{c}{ Return period } & 2 & 5 & 10 & 25 & 50 & 100 \\
\hline probability & & 0.5 & 0.2 & 0.1 & 0.04 & 0.02 & 0.01 \\
\hline $\begin{array}{c}\text { Mother } \\
\text { wavelet }\end{array}$ & $\begin{array}{c}\text { Decomposition } \\
\text { level }\end{array}$ & & & & & & \\
\hline Haar & 1 & 2.22 & 6.14 & 8.19 & 10.37 & 11.79 & 13.06 \\
Haar & 2 & 3.20 & 8.59 & 11.40 & 14.41 & 16.35 & 18.10 \\
Haar & 3 & 4.62 & 11.74 & 15.47 & 19.44 & 22.01 & 24.32 \\
Haar & 4 & 6.63 & 15.97 & 20.86 & 26.06 & 29.43 & 32.45 \\
Haar & 5 & 10.10 & 23.51 & 30.53 & 38.01 & 42.84 & 47.18 \\
Haar & 6 & 15.28 & 33.44 & 42.93 & 53.05 & 59.58 & 65.46 \\
Haar & 7 & 22.14 & 44.50 & 56.18 & 68.65 & 76.70 & 83.94 \\
Haar & 8 & 33.08 & 61.24 & 75.96 & 91.66 & 101.80 & 110.92 \\
\hline db4 & 1 & 2.29 & 6.37 & 8.50 & 10.77 & 12.23 & 13.55 \\
db4 & 2 & 3.35 & 8.88 & 11.77 & 14.86 & 16.85 & 18.65 \\
db4 & 3 & 4.82 & 12.12 & 15.94 & 20.01 & 22.64 & 25.01 \\
db4 & 4 & 7.01 & 16.87 & 22.03 & 27.53 & 31.08 & 34.28 \\
db4 & 5 & 10.06 & 23.28 & 30.19 & 37.56 & 42.33 & 46.61 \\
db4 & 6 & 15.16 & 32.60 & 41.71 & 51.43 & 57.71 & 63.36 \\
db4 & 7 & 21.97 & 45.36 & 57.59 & 70.64 & 79.06 & 86.64 \\
db4 & 8 & 33.81 & 63.93 & 79.67 & 96.45 & 107.30 & 117.05 \\
\hline
\end{tabular}

The approximation time series was applied to estimation of flood risk. The results of this method with two functions were presented on Table 6 .

The tabulated results show that the appropriate selection of mother wavelet can present almost same result at a

determined decomposition level (fig. 8). But the decomposition level made the significant change in estimation of flood discharge (fig. 9). Although the decomposition levels cannot increase more than eight because of data over training.

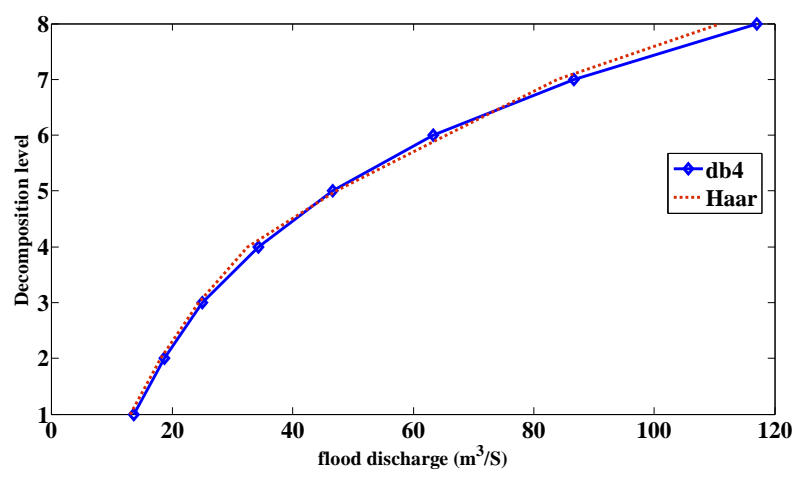

Fig 8: Flood discharge estimation for 100 year return period by Haar and db4 mother wavelet 


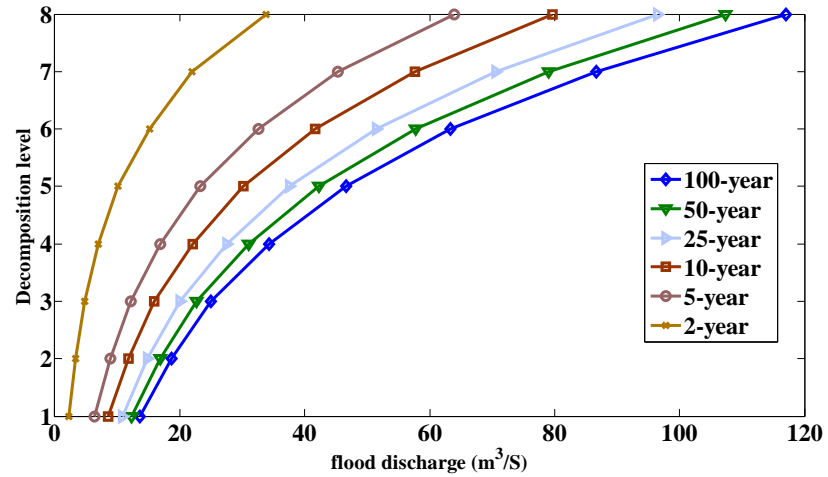

Fig 9: Flood discharge estimation in various return periods by $\mathrm{db} 4$

\section{CONCLUSIONS}

Traditional approaches for flood discharge estimation are built upon the stationary assumption. This assumption is challenged by several recent studies. This research presented a non-stationary model for flood discharge estimation. The model was tested with a time series of discharge data from Tamer hydrometric station that located in North of Iran.

The obtained results for proposed non-stationary model showed that decomposition level have a vital role in estimated discharge. The estimated discharges are increasing respect to enhancing in decomposition levels. For instance, in 100-year return period, the estimated discharges are increased from $13.55 \mathrm{~m}^{3} / \mathrm{sec}$ to $117.05 \mathrm{~m}^{3} / \mathrm{Sec}$ for 1 and 8 decomposition levels by db4 mother wavelet, respectively. On the other hand, the different mother wavelet cannot change the estimated discharge when the mother wavelet was selected based on time series formation.

As a whole, this study presents an appropriate method to estimate flood discharge in all watersheds including stationary and non-stationary discharge data.

\section{ACKNOWLEDGEMENTS}

This paper is the result of the research plan "Application of wavelet transform for flood estimating (Case study: Golestan Catchment)" in Islamic Azad University, Roudsar and Amlash branch, department of civil engineering.

\section{REFERENCES}

[1] V. Chow, D. Maidment and L. Mays, "Applied hydrology". Vol. $2^{\text {nd }}$ edition,McGraw-Hill Press, New York, 2013.

[2] V.V. Srinivas, S.Tripathi, A.R.Rao and R. S. Govindaraju, "Regional Flood Frequency Analysis by Combining Self-Organizing Feature Map and Fuzzy Clustering", Journal of Hydrology, Vol. 348, pp. 148-166., 2008.

[3] C. Shu and T.B.M.J. Ouarda, "Regional Flood frequency Analysis at Ungaged Sites Using the Adaptive Neuro- Fuzzy Interface System", Journal of Hydrology, Vol.349., pp.31-43., 2008.

[4] K. Haddad and A. Rahman, "Regional Flood Frequency Analysis in eastern Australia: Bayesian GLS Regression-Based Methods within Fixed Region and ROI Framework-Quantile Regression vs. Parameter Regression Technique", Journal of Hydrology, Vol. 430-431., pp. 142-161., 2012.

[5] M. Lecrec and T.B.M.J. Ouarda, "Non-stationary Regional Flood Frequency Analysis at Ungaged Sites", Journal of Hydrology, Vol. 343., pp. 254265., 2007.

[6] G. Villarini, J.A. Smith, F. Serinaldi, B. Jerad, P.D. Bates and W.F. Krajewski, "Flood Frequency Analysis for non-stationary Annual Peak Records in an Urban Drainage Basin", advances in water resources, Vol. 32., pp. 1255-1266., 2009.

[7] J.H. Heo, D.C. Boes and J.D. Salas, "Regional flood frequency analysis based on a Weibull model: Part 1 . Estimation and asymptotic variances, Journal of Hydrology, Vol. 242. pp. 157-170., 2001 a.

[8] J.H. Heo, J.D. Salas and D.C. Boes, "Regional Flood Frequency Analysis Based on a Weibull Model: part2. Simulations and Applications, Journal of Hydrology, Vol. 242. pp 171-182., 2001b.

[9] C. Shu and D.H. Burn, "Homogeneous Pooling Group Delineation for Flood Frequency Analysis Using a fuzzy Expert System with Genetic Enhancement", Journal of Hydrology, Vol. 291, pp. 132-149., 2004.

[10] L. Karthikeyan and D.N. Kumar, "Predictability of non-stationary time series using wavelet and EMD based ARMA models", Journal of Hydrology, Vol. 502., pp. 103-119., 2013.

[11] Y.F. Sang, "A review on the applications of wavelet transform in hydrology time series analysis", Atmospheric Research, Vol. 122., pp. 8-15., 2013.

[12] S. Shahabi and M. R. Hessami Kermani, "Flood frequency analysis using density function of wavelet (case study: Polroud River)", Journal of Applied Research in Water and Wastewater, Vol. 2(1), pp. 129-135., 2015.

[13] S. Shahabi, M. J Khanjani and M. R. Hessami Kermani, "Hybrid Wavelet-GMDH Model to Forecast Significant Wave Height", Water Science and Technology: Water Supply, In Press, 2016. 